\title{
Do caos ao cosmos: um ensaio sobre as semelhanças simbólicas entre Estado e religião
}

\author{
Daniel Nunes Pereira*
}

\begin{abstract}
Resumo: 0 presente ensaio pretende traçar paralelos entre os dois principais fenômenos da experiência humana, quais sejam, o Estado e a religião. As semelhanças têm como eixo principal as categorias espaço/tempo, no qual investigamos a importância dos rituais e signos. Ademais, busca-se entender como os símbolos nacionais e estatais contribuem para a visão de mundo dos indivíduos e sua relação com as instituições políticas.
\end{abstract}

Palavras-chave: cosmogonia, semiótica, Estado, religiões, fenomenologia.

\section{Primeira parte}

Os símbolos nacionais e estatais por vezes prendem nossa atenção, porque, talvez, eles pareçam esclarecer algo sobre nossa experiência política e histórica. Evocam-se questões sobre a origem e o sentido do Estado. A reductio a campos ontológicos da teoria política e províncias meramente teóricas da semiótica não parecem bastar.

$\mathrm{Na}$ experiência religiosa parecem residir as repostas. Não a escolhemos por razões que excedem o espírito científico de investigação, mas por ser uma abordagem eminentemente inesperada e surpreendentemente satisfatória. Ora, qual o primeiro fenômeno que o homem tenta explicar senão seu temor e reverência a um mundo que parece mágico e sagrado?

A experiência religiosa é de tamanho impacto histórico e social que parece afetar todos os outros fenômenos, suas estruturas essenciais e os objetos a eles correspondentes. Na manifestação cultural da consciência da dependência com relação a outros seres de caráter sobrenatural reside o aspecto eminentemente humano da religião. De maneira diametralmente oposta, a manifestação cultural da consciência da dependência com relação a outros seres humanos é o que configura a política. Com base no trabalho de Émile Durkheim, entendemos a religião como a principal esquematização de normalização da vida social e compreensão do mundo. É no pensamento religioso que os primeiros sistemas de explicação da natureza

\footnotetext{
${ }^{*}$ Graduado em Direito - UFF.
} 
e do homem, e das instituições sociais são desenvolvidos, mesmo que colateralmente (DURKHEIM, 2009, p. 38). Em comparação com o condão de revelação da vontade e do poder sobrenatural sobre os homens, vemos que a política exerce um movimento inverso ao cultural quando revela a vontade e o poder de alguns homens sobre os demais.

Baseando-se nessa comparação entre política e religião e buscando uma convergência entre os dois fenômenos, o presente ensaio pretende, portanto, tentar explicar como se formam os símbolos estatais e nacionais. Ademais, tenta entender a origem, a contingência e a estrutura da experiência ao fenômeno do Estado.

Entretanto, nesta empreitada intelectual, mister se faz ressaltar algumas questões que podem levar o leitor a conclusões equivocadas. Numa tentativa de tornar a proposta deste ensaio mais dinâmica, e por amor ao correto uso dos nomes e títulos dos fatos e fenômenos, optamos por uma definição mais elástica de Estado ${ }^{1}$ - "todas as sociedades políticas que, com autoridade superior, fixaram as regras de convivência de seus membros" (DALlaRI, 2000, p. 52). Diverso em alguns pontos, mas tangente em certa medida, tomamos também a perspectiva juspositivista de Kelsen, segundo a qual o Estado é entendido como uma unidade especificamente legal, e, dentro das propostas ora estudadas, inclusive no que trata das normas e práticas religiosas de cunho normativo (KELSEN, 2000, p. 271-275).

Com as devidas ressalvas, explica-se que o presente ensaio propõe analisar as semelhanças entre o cosmos Estatal e o mundo religioso pelos aspectos: 1) do tempo heterogêneo; 2) das roturas no espaço; 3) do entendimento da razões primordiais do Estado como solução que aproxime este aos seus súditos.

\section{Segunda parte}

O pensamento religioso é resultado de uma noção e uma potência de transcendência que há no ser humano, e isso gera, por sua vez, as narrativas mitológicas. Então, questiona-se a priori: como nasce a transcendência? Tomaremos como fio

\footnotetext{
1 Ao referirmo-nos ao Estado em sua conotação generalista, afastamo-nos das posições de Eduard Meyer, Wilhem Koppers, Giorgio Balladore Pallieri, Carl Schmidt e alguns outros autores de doutrina westphaliana.
} 
condutor o disposto por Peter Sloterdijk (2009, p. 20-24) segundo o qual estão na gênese da transcendência o desconhecimento do lento (transgeracional), o desconhecimento do violento, a impossibilidade de alcançar o outro, e, talvez o mais importante, o fato de a consciência humana comportar a faculdade de apresentar uma inteligência que a ultrapasse. Por outro lado, ainda nessa questão, há também a profundidade do ser humano, a qual alegadamente resta em sua dimensão religiosa, sintonizada quando algo toca incondicionalmente o indivíduo. Essa profundidade do ser humano, na verdade, jaz no absurdo de sua existência, e sua incapacidade de lidar com isso dá vazão a pretensas manifestações do sagrado, a exercícios de imaginação e a consequente criação dos chamados mitos. 0 "sagrado", portanto, é um método de suportação e resignação ante uma existência que tem o condão de nos aniquilar, e manifesta-se não apenas nas coisas cotidianas mas pelas coisas cotidianas, segundo Eliade (2010). Na hierofania (irrupção do sagrado), na experimentação do alegado sopro religioso, toda a natureza pode manifestar-se como sacralidade cósmica.

Os mitos, por sua vez, são gerados e estruturados mediante roturas espaçotemporais. As religiões em geral tratam o tempo (assim como o espaço) de maneira heterogênea; há uma temporalidade sagrada e uma profana. Aquela, que por hora nos interessa, traz em si o sentido da passagem do caos para o cosmos, ou seja, a rotura no tempo tem como finalidade explicar a organização do mundo. Essa marcação temporal relaciona-se de maneira indissociável com o rito, o qual repete e teatraliza o mito cosmogônico.

De acordo com Eliade (2010), a cosmogonia apresenta-se de duas maneiras: a primeira insere o cosmos em um ciclo, com infinitas criações e destruições da existência, o que se relaciona com as primeiras comunidades agrícolas e suas observações das estações do ano e as colheitas cíclicas; a segunda entende a existência do cosmos como linear, havendo apenas um começo e fim. Esta segunda maneira de entender a cosmogonia particularmente interessa ao presente ensaio, por ser típica de religiões monoteístas e milenaristas.

O momento da criação do mundo, para Eliade (2010, p. 71), é tido como um "tempo puro, forte e sagrado"; é idealizado e repetido por ritos, tem a função de explicar o mundo, mas também de justificar e exemplificar toda a estrutura social. 
Esse momento mítico geralmente é precedido pelo caos, ou alguma figura que o representa, e a vitória ou a potestade de um ser sagrado consubstancia-se na própria cosmogonia. Por exemplo, na mitologia babilônica, o deus Marduk, após vencer o dragão Tiamat ${ }^{2}$, dá origem ao cosmos com o corpo esquartejado do monstro e cria o homem com o sangue do demônio Kingu. Na tradição judaico-cristã há menos riqueza literária, mas o sentido é o mesmo quando Elohim/Javé exerce sua ilimitada potestade ao criar os céus e a terra ex nihilo. De maneira geral, o "monstro do abismo" que enfrenta a força divina ordenadora trata de uma relação semelhante à trabalhada por Schmitt (1992) na perspectiva do Estado sempre pronto a enfrentar soberanamente a possibilidade real do inimigo. Para o referido autor, um raciocínio "otimista" da natureza humana tende a conduzir à abolição da lógica política. Há, na verdade, um nexo nas teorias políticas que se pautam em dogmas teológicos a respeito do pecado (idem, p. 91). 0 pecado pressupõe um criador bondoso, assim como o "inimigo" pressupõe o soberano. Na verdade, tudo isso se insere na proposição schmittiana de que "todos os conceitos significativos da doutrina do Estado moderna são conceitos teológicos secularizados" (idem, p. 18).

O mito da criação do Estado não se distancia muito das narrativas religiosas, o núcleo narrativo, um poder inefável que traz ordem ao caos, repete-se. No estado de natureza, Bellum omnia omnes, emana o poder criador do cosmos. Assim como o universo surge do cadáver de Tiamat, o Estado surge do caos no estado de natureza. Marduk, Alah ou Elohim faz-se na vontade humana de acabar com o caos, de pôr fim ao estado de guerra. Cabe aqui não confundir a comparação ora feita entre deidades e a inspiração quando da criação dos Estados nacionais, não evocamos aqui de maneira alguma qualquer sentido divino ou paranormal nas ações humanas, não se defende intromissão divina em assuntos mundanos. Ocorre, portanto, uma comparação entre o princípio de tudo, narrado pelos mitos e o começo do próprio Estado. Há, portanto, o Mythos do Estado, e, por uma análise semiótica, há congruências entre os signos e ritos estatais e religiosos.

\footnotetext{
2 Esse Dragão primordial costuma a ser referenciado também como Serpente Marinha (FotENROSE, 1980, p. 153), ou seja, simboliza as mesmas águas cósmicas escuras relatadas no Gênesis, as quais, por sua vez, simbolizam o amorfo, aquilo que ainda está para ter uma forma. 0 próprio abismo primordial encarado por Javé é nomeado Rahab, que no Livro de Isaías e no folclore judeu é mencionado como um dragão marinho.
} 
Há uma força criadora de poderes ilimitados (dentro do contexto) na cosmogonia Estatal, bem como nos mitos religiosos. A vontade popular na fundação do espaço político é o demiurgo da criação do mundo estatal, trabalha por imitatio dei. Essa vontade, permeada pela ação de algum personagem histórico ou não, é o que traz o signo da transcendência, o ganz andere ${ }^{3}$, a fascinação. As posteriores narrativas e festividades referentes à criação do Estado hão de reverenciar as gestas do "mundo" in statu nascendi.

O surgimento do mito do Estado é uma tentativa de explicar a origem e o sentido do espaço político no qual se vive. Esse fenômeno pode ser natural, às vezes oral ou por vezes presente na historiografia tradicional (como nos países escandinavos e as referências às sagas vikings) ou, em outros casos, é oficialmente originado no próprio aparato ideológico do Estado ou de algum grupo social relevante (como no caso de $A$ Eneida, ou nos manuais de história da Era Vargas).

Em ambos os casos, o mito do Estado, assim como na cosmogonia religiosa, tem a função de incutir nos cidadãos um sentimento de pavor diante de algo inefável, diante de um mysterium tremendum et fascinans. 0 Estado, portanto, por meio de seus mitos de criação e suas consequentes ritualizações, exala uma esmagadora potestade diante dos indivíduos, causa assim uma experiência "quasi-numinosa". Ora, qual não é a reação popular à cerimônia de posse do Presidência da República, ou da parada militar de 7 de setembro? Igualmente não se verifica uma experiência de espanto, admiração e emoção incontida nas festividades de 4 de julho nos Estados Unidos, ou o $1^{\text {o }}$ de dezembro em Portugal?

Essas festividades nacionais nada mais são do que os ritos do Estado. Assim como no âmbito religioso, tenta-se resgatar uma época em que a nação era "pura e forte"; os feriados históricos nacionais e suas festividades fazem com que todos participem ritualmente e se tornem contemporâneos do illud tempus do Estado, o qual com base nesses ritos se regenera, volta em essência in illo tempore.

\footnotetext{
3 Ganz Andere: a tradução aproximada seria "totalmente outro", mas o real significado é o de alteridade radical do ser humano e seu temor reverencial pelo sagrado. 0 termo foi originalmente utilizado por Rudolf Otto em seu tratado teológico Das Heilige.
} 


\title{
Terceira parte
}

Relacionando-se diretamente com a questão da força criadora do mundo estatal e sua explicação quanto à contingência e finalidade, há a problemática da natureza sui generis do Estado. De acordo com Norman Barry (1989, p. 192):

\begin{abstract}
[...] we do in normal speech, and in political argument especially, refer to the state as if it were an institution, or perhaps complex of institutions qualitatively different from others in society. [...] Thus the most casual observation of the features of the modern state, such as determinate boundaries, centralized authority, the claim (not always successful) to a monopoly of coercion, and the assumption of the power of law creation (or sovereignty) suggests an artifice or contrivance which stands in need of some external justification (from ethics and perhaps political economy) rather than something intrinsic to the nature of man. The very fact that most states are product of force, as Hume argued, suggests this.
\end{abstract}

Esse constructo, o Estado, é feito à imagem da cosmogonia. De acordo com Eliade (2010, p. 46), "a instalação num território equivale à fundação de um mundo" e ele prossegue a demonstrar o paralelo entre a cidade e o cosmos:

\begin{abstract}
Visto que "nosso mundo" é um Cosmos, qualquer ataque exterior ameaça transformálo em "Caos". E dado que "nosso mundo" foi fundado pela imitação da obra exemplar dos deuses, a cosmogonia, os adversários que o atacam são equiparados aos inimigos dos deuses, aos demônios, e sobretudo ao arquidemônio, o Dragão primordial vencido pelos deuses nos primórdios dos tempos. 0 ataque de "nosso mundo" equivale a uma desforra do Dragão mítico, que se rebela contra a obra dos deuses, o Cosmos, e se esforça por reduzi-la ao nada. Os inimigos enfileiram-se entre as potências do Caos. Toda destruição de uma cidade equivale a uma regressão ao Caos. Toda vitória contra o atacante reitera a vitória exemplar do Deus contra o Dragão (quer dizer, contra o "Caos"). É por essa razão que o faraó era assimilado ao deus Rã, vencedor do dragão Apophis, ao passo que seus inimigos eram identificados a esse Dragão mítico. Dario considerava se um novo Thraetaona, herói mítico iraniano de quem se dizia ter matado um Dragão de três cabeças. Na tradição judaica, os reis pagãos eram apresentados sob os traços do Dragão: tal é o Nabucodonosor descrito por Jeremias e o Pompeu apresentado nos Salmos de Salomão (idem, ibidem).
\end{abstract}

No presente esforço teórico seguimos além do exposto por Eliade, pois traçamos um paralelo entre a cosmogonia do Estado e a narrativa religiosa não apenas pelo aspecto da experiência fenomenológica do homo religiosus enquanto artífice de instituições mas também como a possibilidade de este "cosmos-Estado" ter um mito próprio que emule as narrativas sagradas, mas sem ter uma relação de dependência com estas, estando, portanto, no plano do profano.

As capitais, algumas cidades, certos monumentos e centros cívicos formam o eixo do Cosmos do Estado. Assim como no tempo, no espaço faz-se uma rotura e 
este se torna heterogêneo. As rupturas na homogeneidade do espaço estatal fazem com que alguns lugares se tornem mais importantes em detrimento dos demais. Semelhante ao fenômeno do sagrado, no Estado este "centro do mundo" é um pilar que sustenta todos os níveis da existência, ou seja, é dali que todas as estruturas do Estado ab origine se mantêm.

Inexoravelmente inserido no eixo do cosmos estatal, bem como no centro da Criação mítica, jaz o "Detentor do Poder" e "mantenedor da existência" - a divindade, politicamente representada funcionalmente no soberano. Dessa noção decorre, dentro de um prisma eminentemente hobbesiano, a questão da obediência unívoca. Paralelamente é possível evocar algumas noções de dominação baseando-se na obra de Weber (1979, p. 551-558), sobretudo na dominação carismática, na qual há habilidades mágicas, heroísmo, revelações, poder intelectual ou de oratória, enfim, o inaudito e extracotidiano que trazem consigo a devoção pessoal. Podemos supor que as estrutura semelhantes entre cosmogonias mítica e estatal, conforme relatado, contribuem para o aparecimento desse tipo de força dominadora.

\section{Quarta parte}

Os pilares da criação, no caso ora em exame, são também referências, signos desse imago mundi estatal. Nesse sentido, as roturas espaciais confundem-se com as rupturas temporais, ou seja, hic et nunc; todos se tornam contemporâneos às justificativas e significados últimos do próprio Estado. 0 alcance desses signos delimitará de maneira definitiva a envergadura do poder estatal.

Por todo o exposto vemos a importância dos simbolismos do Estado; eles aproximam o cidadão das bases ontológicas do espaço político onde vive. A assunção da vontade humana como demiurgo na cosmogonia estatal e seu sentido como vitória sobre o Dragão Primordial do caos nos faz lançar olhares diferentes, compreensivos, porém, críticos sobre as gestas e os signos nacionais. As origens metafísicas e ontológicas do fenômeno entendido como Estado, se corretamente compreendidas, podem permitir-nos uma aproximação mais fiel ao mecanismo gerador de tudo. Todos os símbolos, as datas e os lugares que formam nosso Weltanschauung podem ter seu significado aprimorado; o imitatio dei que representam 
pode ser entendido como mais presente e menos distante, mais imanente e menos uraniano e transcendente.

\section{Referências}

Barry, N. (1989). "The State and Legitimacy”. In: GriffiThS, A. P. (org.). Key Themes in Philosophy. Cambridge, The Press Syndicate of The University of Cambridge The Royal Institute of Philosophy.

DALLARI, D. A. (2000). Elementos de teoria geral do Estado. São Paulo, Saraiva.

DuRKheim, E. (2009). As formas elementares da vida religiosa. São Paulo, Martins Fontes.

EliAde, M. (2010). O sagrado e o profano: a essência das religiões. São Paulo, Martins Fontes.

Fotenrose, J. (1980). Python: a study of Delphic myth and its origins. Los Angeles, University of California Press.

Kelsen, H. (2000). Teoria geral do direito e do Estado. São Paulo. Martins Fontes.

SchmitT, C. (1992). O conceito do político. Petrópolis, Vozes.

SLOTERDiJK, P. (2009). A loucura de Deus: do combate dos três monoteísmos. Lisboa, Relógio D'Água Editores.

Weber, M. (1979). Sociologia. São Paulo, Ática, n. 13 (Coleção grandes cientistas sociais).

Recebido em março/2011

Aprovado em setembro/2011 